\title{
Atividade biológica e quantificação de \\ compostos bioativos em extrato de \\ erva-mate e sua aplicação em \\ hambúrguer de peixe
}

\section{Biological activity and quantification of bioative compounds in yerba mate extract and its application in fish hamburger}

\section{Andressa Tonet ${ }^{* 1}$ (D), Ricardo Fiori Zara ${ }^{1}$, Tatiana Shioji Tiuman ${ }^{1}$}

${ }^{1}$ Universidade Tecnológica Federal do Paraná (UTFPR), Programa de Pós-graduação em Processos Químicos e Biotecnológicos, Campus Toledo, Toledo/PR - Brasil

\begin{abstract}
*Autor Correspondente: Andressa Tonet, Universidade Tecnológica Federal do Paraná (UTFPR), Programa de Pós-graduação em Processos Químicos e Biotecnológicos, Campus Toledo, Rua Cristo Rei, 19, CEP: 85902-490, Toledo/PR - Brasil, e-mail: andressatonet@hotmail.com
\end{abstract}

Cite as: Tonet, A., Zara, R. F., \& Tiuman, T. S. (2019). Biological activity and quantification of bioative compounds in yerba mate extract and its application in fish hamburger. Brazilian Journal of Food Technology, 22, e2018054. https://doi.org/10.1590/1981-6723.05418

\begin{abstract}
Resumo
A enva-mate possui compostos biologicamente ativos com aplicação industrial. Cafeína, rutina e ácido clorogênico presentes neste produto possuem atividade antioxidante e o último ainda é antimicrobiano. Este estudo objetivou avaliar a atividade biológica do extrato de enva-mate e quantificar compostos bioativos, bem como aplicar o extrato em hambúrguer de peixe para determinar seu poder conservante. A atividade antioxidante foi avaliada por DPPH (2,2-difenil1-picrihidrazila) e FRAP (poder de redução do ferro). Foram quantificados compostos fenólicos totais e flavonoides por espectrofotometria, e cafeína, rutina e ácido clorogênico, por cromatografia líquida de ultraeficiência. A atividade antimicrobiana foi determinada pela concentração inibitória mínima (CIM). Testaram-se associações de extrato com o conservante sintético butil-hidroxi-anisol (BHA). Hambúrgueres de peixe foram incorporados com extrato de erva-mate e foram feitas análises de composição centesimal, oxidação lipídica e microbiológica por 28 dias. $\mathrm{O}$ extrato apresentou para DPPH IC 50 de 7,91 $\mathrm{g} \mathrm{mL} \mathrm{mL}^{-1}$, FRAP de 4.922,67 $\mu$ mol de Fe (II) g ${ }^{-1}$, 104,54 EAG g-1 de fenólicos totais, 23,11 EQ g ge $^{-1}$ flavonoides e 49,6, 34,5 e 23,1 $\mathrm{mg} \mathrm{g}^{-1}$ de ácido clorogênico, cafeína e rutina, respectivamente. $O$ extrato mostrou CIM de 10, 5 e $10 \mathrm{mg} \mathrm{mL}^{-1}$ contra Escherichia coli, Staphylococcus aureus e Salmonella enterica, respectivamente. A combinação de extrato com BHA reduziu a quantidade de consenvante sintético para a mesma atividade antioxidante e mostrou caráter aditivo para S. aureus. Os hambúrgueres de peixe com 1\% de extrato ou com BHA exibiram diferença estatística na contagem de mesófilos em relação ao controle. Assim, observou-se que o extrato de erva-mate apresentou atividade biológica e o crescimento de mesófilos foi inibido nos hambúrgueres de peixe incorporados com BHA ou 1\% de extrato, de forma que os compostos fenólicos quantificados seriam os prováveis agentes conservantes.
\end{abstract}

Palavras-chave: Atividade antioxidante; Atividade antimicrobiana; Checkerboard; Conservantes naturais; Ilex paraguariesis; Oreochromis niloticus. 


\begin{abstract}
The yerba mate has a high content of biologically active compounds with industrial application. Caffeine, rutin and chlorogenic acid present in this product have antioxidant activity and the latter one is also an antimicrobial agent. This \paper aimed to assess the biological activity of yerba mate extract and quantify its bioactive compounds, as well as apply the extract in fish hamburger to determine its preservative activity. The antioxidant power was evaluated by DPPH (2,2-diphenyl-1-picrylhydrazyl) and FRAP (ferric reducing antioxidant power). Total phenolic compounds and flavonoids were quantified by spectrophotometry, and caffeine, rutin and chlorogenic acid by ultra-performance liquid chromatography. The antimicrobial activity was assessed by Minimum Inhibitory Concentration (MIC). Associations of extract with the synthetic preservative butyl hydroxyanisole (BHA) were tested. Fish hamburgers incorporated with yerba mate were prepared; centesimal composition, lipid and microbiological oxidation were carried out during 28 days. Results: DPPH IC 50 of $7.91 \mu \mathrm{g} \mathrm{mL}^{-1}$ in the extract, FRAP of $4922.67 \mu \mathrm{mol}$ for Fe (II) g ${ }^{-1}, 104.54 \mathrm{EAG} \mathrm{g}^{-1}$ of total phenolics, $23.11 \mathrm{EQ} \mathrm{g}^{-1}$ of flavonoids, and $49.6,34.5$ and $23.1 \mathrm{mg} \mathrm{g}^{-1}$ of chlorogenic acid, caffeine and rutin, respectively. The extract presented a CIM of 10, 5 and $10 \mathrm{mg} \mathrm{mL}^{-1}$ against Escherichia coli, Staphylococcus aureus and Salmonella enterica, respectively. The combination of extract and BHA reduced the amount of synthetic preservative for the same antioxidant activity and presented an additive effect to $S$. aureus. The fish hamburgers with $1 \%$ of extract or with BHA showed statistical difference in mesophiles counting from the control group. Thus, the yerba mate extract presented biological activity and the growth of mesophiles was inhibited in fish hamburguers incorporated with BHA or $1 \%$ of extract, indicating that the quantified phenolic compounds are likely to be preservative agents.
\end{abstract}

Keywords: Antioxidant activity; Antimicrobial activity; Checkerboard; Natural preservative; llex paraguariesis; Oreochromis niloticus.

\title{
1 Introdução
}

Há milênios, as plantas são fontes inspiradoras de produtos ou derivados com potenciais atividades biológicas, servindo como protótipos de moléculas biologicamente ativas sintetizadas para aplicação em larga escala na indústria (Atanasov et al., 2015).

Os estudos de derivados vegetais não se limitam apenas à investigação de estrutura biologicamente ativa e processos de isolamentos dos compostos, mas também a sua aplicação à indústria, principalmente alimentícia. Portanto, nos últimos anos, o interesse nas plantas tem focado em sua introdução em produtos alimentares com o intuito de otimizar sua vida útil, sem alterar significativamente suas características organolépticas ou nutricionais (Tiwari et al., 2009).

Um exemplo de planta que possui compostos biologicamente ativos é a erva-mate (Ilex paraguariensis, St. Hill), planta muito cultivada na América do Sul (Argentina, Brasil, Paraguai e Uruguai) (Pagliosa et al., 2010). É normalmente consumida na forma de mate, tererê e chá, e seu consumo no Brasil pode alcançar valores aproximados de $5 \mathrm{~kg}$ per capita por ano (Cardozo Junior \& Morand, 2016).

Numerosos compostos fitoquímicos ativos foram identificados na erva-mate, responsáveis por diversas atividades biológicas. De acordo com Heck \& De Mejia (2007), a cafeína e a rutina possuem atividade antioxidante; já o ácido clorogênico, além de potencial antioxidante, detém propriedades antimicrobianas.

Considerando que a erva-mate possui potencial antimicrobiano e antioxidante, atividades já desempenhadas por conservantes sintéticos em alimentos, o presente trabalho teve como objetivos avaliar a atividade biológica e quantificar os compostos bioativos da erva-mate, e aplicar seu extrato em hambúrguer de peixe para avaliar sua atividade conservante. 


\section{Material e métodos}

\subsection{Material vegetal e butil-hidroxi-anisol}

O extrato seco de erva-mate (Ilex paraguariensis - lote A80916) foi gentilmente cedido pela empresa Heide Extratos Vegetais, situada em Pinhais-PR. O mesmo foi preparado em solução hidroalcoólica e seco por spray dryer, cuja velocidade de secagem foi de $7 \mathrm{~L} /$ hora, com temperatura de entrada de $180{ }^{\circ} \mathrm{C}$ e de saída de $90^{\circ} \mathrm{C}$, sem a adição do veículo maltodextrina.

O conservante butil-hidroxi-anisol (BHA - lote ABH015C010) foi adquirido da empresa Henrifarma Produtos Químicos e Farmacêuticos de Cambuci, São Paulo.

\subsection{Atividade antioxidante}

Os testes para avaliação da atividade antioxidante do extrato e do BHA foram realizados pelos métodos de captura do radical livre 2,2-difenil-1-picrihidrazila (DPPH) e de poder de redução do complexo férrico (FRAP).

O teste de DPPH se baseou no método descrito por Boroski et al. (2015), com adaptações. Já o teste de FRAP procedeu conforme descrito pela Embrapa (Rufino, 2007), com adaptações.

\subsection{Quantificação de compostos fenólicos e flavonoides totais}

A quantificação dos compostos fenólicos no extrato de erva-mate (llex paraquariensis) foi realizada pelo método de Folin-Ciocalteu e de flavonoides totais, por análises espectrofotométricas. Tanto o teste para quantificação de compostos fenólicos quanto o teste de flavonoides totais foram realizados segundo Boroski et al. (2015).

\subsection{Atividade antimicrobiana do extrato de erva-mate (llex paraguariensis) e BHA (butil-hidroxi- anisol)}

A atividade antibacteriana do extrato seco de erva-mate e do BHA foi testada utilizando a metodologia da determinação da Concentração Inibitória Mínima (CIM), com adição do corante cloreto de trifeniltetrazólio (CTT) a 0,5\%, e Concentração Bactericida Mínima (CBM) (Clinical and Laboratory Standards Institute, 2015). Os microrganismos testados foram as bactérias Salmonella enterica sorovar Typhi (ATCC06539), Staphylococcus aureus (ATCC14458) e Escherichia coli (ATCC10536).

\subsection{Análise de interação antimicrobiana por checkerboard}

O método de checkerboard consistiu na diluição seriada do BHA e extrato de erva-mate em microplaca de 96 poços, conforme descrita por Endo et al. (2010), que resulta em diferentes combinações destes ativos. O cálculo de ICIF (Índice de Concentração Inibitória Fracionada) avalia e classifica a interação dos compostos, levando em consideração a razão da concentração inibitória mínima do composto associado e isolado.

Uma escala de valores $(\leq 0,5$ a $>2)$ para o ICIF foi utilizada como referência padrão para efeito de comparação com os valores obtidos em nossa pesquisa (Nogueira, 2012).

\subsection{Desenvolvimento e validação de metodologia analítica para quantificação de compostos de erva-mate (Ilex paraguariensis) por cromatografia líquida de ultra eficiência}

O desenvolvimento do método analítico para avaliação de cafeína, rutina e ácido clorogênico no extrato de erva-mate foi realizado por Cromatografia Líquida de Ultra Eficiência (CLUE). O cromatógrafo utilizado foi da marca Waters acquity $\mathrm{H}$-class equipado com injetor (modelo SDI), bomba quaternária (QSM), forno (MP e detector PDA (UPL). O software utilizado para aquisição e análise de dados foi o Empower ${ }^{\mathbb{B}} 3.0$. A separação cromatográfica foi realizada com coluna C18 (octadecilsilano) Waters Acquity BEH $100 \mathrm{~mm} \times 2,1 \mathrm{~mm} \times 1,7 \mu \mathrm{m}$. A fase móvel foi composta de ácido trifluoracético $0,1 \%$ (TFA) e metanol, com gradiente de concentração que iniciou com $80 \%$ de TFA $0,1 \%$ e $20 \%$ de metanol, em um minuto foi 
para $60 \%$ de TFA $0,1 \%$ e $40 \%$ de metanol, em seis minutos $43 \%$ de TFA $0,1 \%$ e $57 \%$ de metanol, em 6,2 minutos retornou à condição inicial $(80: 20)$, na qual se manteve até sete minutos.

As amostras foram preparadas na concentração de $100 \mu \mathrm{g} \mathrm{mL} \mathrm{mL}^{-1}$ em água ultrapura e filtradas em membrana hidrofílica PVDF (difluoreto de polivinilideno) de poro 0,22 $\mu \mathrm{m}\left(\right.$ Merck $\left.^{\circledR}\right)$. O Fluxo utilizado foi de $0,35 \mathrm{~mL}$ $\min ^{-1}$, temperatura da coluna de $45{ }^{\circ} \mathrm{C}$, temperatura do injetor de $5{ }^{\circ} \mathrm{C}$ e volume de injeção de $3 \mu \mathrm{L}$. $\mathrm{O}$ comprimento de onda utilizado para avaliação dos compostos foi de $254 \mathrm{~nm}$.

A validação da metodologia analítica foi realizada conforme guia Q2 (R1) da Conferência Internacional de Harmonização (International Council for Harmonisation, 2005) e contemplou os parâmetros de especificidade, linearidade, limite de quantificação e detecção, precisão, exatidão e robustez (International Council for Harmonisation, 2005). Os critérios de aceitação para repetibilidade, intermediária e recuperação foram calculados considerando o limite de quantificação individual, conforme guia de validação de métodos em análise farmacêuticas (Ermer \& Miller, 2006), documento de orientação sobre validação de métodos analíticos do Imnetro (Coordenação Geral de Acreditação do Inmetro, 2011) e da RDC 166 de julho de 2017 (Brasil, 2017). As especificações para os valores de precisão foram de 10\% para o nível mais baixo (1,0\%) e $5 \%$ para os níveis mais altos (5,0 e 10,0\%). O critério de aceitação para exatidão foi de 80 a $120 \%$ (para o nível de 1,0\%) e 90 a 110\% (para os níveis de 5,0 e 10,0\%). O coeficiente de correlação considerado para o parâmetro de linearidade foi $<0,990$.

\subsection{Atividade antioxidante combinada (extrato de erva-mate x BHA)}

Foi proposto um planejamento experimental com dois fatores, três repetições, utilizando o software Design Expert $^{\circledR} 7.0$ da Stat-Ease (Minneapolis, EUA), para avaliar a resposta de cada composto combinado (extrato de erva-mate $\times$ BHA), em diferentes concentrações. A técnica utilizada para a leitura das respostas experimentais foi DPPH, descrita por Boroski et al. (2015).

\subsection{Aplicação do extrato de erva-mate ao hambúrguer de peixe}

O hambúrguer de peixe teve sua formulação base fundamentada no dossiê técnico apresentado por Guerreiro (2006), para preparo de hambúrgueres.

Os filés de tilápia (Oreochromis niloticus) foram adquiridos no comércio da cidade de Toledo-PR. Os insumos básicos utilizados foram sal (marca Cisne, lote 7013161229C), farinha de mandioca branca (marca Pinduca, lote 2P0011) e filé de tilápia (marca Pescados Sereia, lote: 02/01/2017). Os tratamentos testados diferiram entre si quanto a adição e concentração de extrato de erva-mate (Heide Extratos Vegetais, lote A80916) ou butil-hidroxi-anisol (Henrifarma Produtos Químicos e Farmacêuticos, lote ABH015C010). As formulações foram elaboradas conforme apresentado na Tabela 1.

Tabela 1. Formulações testadas para os hambúrgueres de peixe com e sem a adição do extrato de erva-mate (Ilex paraguariensis) e BHA.

\begin{tabular}{ccccccc}
\hline \multirow{2}{*}{ Ingredientes/ Formulações } & F 1 & F 2 & F 3 & F 4 & F 5 \\
\cline { 2 - 6 } & \multicolumn{5}{c}{ Porcentagem de cada insumo } \\
\hline Filés de tilápia & 89,70 & 89,69 & 89,20 & 88,70 & 89,67 \\
Sal de cozinha & 0,30 & 0,30 & 0,30 & 0,30 & 0,30 \\
Farinha de mandioca branca & 10,00 & 10,00 & 10,00 & 10,00 & 10,00 \\
Extrato de erva-mate & - & - & 0,50 & 1,00 & - \\
BHA & - & 0,01 & - & - & 0,03 \\
\hline
\end{tabular}

F: Formulação.

Para o preparo dos hambúrgueres de peixe, foram utilizados equipamentos específicos, dentre os quais o moedor de carnes (SCHARFEN, tipo TC11, modelo TC11) e a hamburgueira (Hamburgatrice automática Planus 2002). Após o preparo, os hambúrgueres foram embalados individualmente em filmes de PVC (policloreto de vinila) e mantidos sob refrigeração a aproximadamente $5{ }^{\circ} \mathrm{C}$, por um período de 28 dias. 


\subsection{Análises físico-químicas do hambúrguer de peixe}

A análise de umidade foi realizada pelo método tradicional em estufa a $105^{\circ} \mathrm{C}$, conforme descrito por Nollet (2004). A quantificação de cinzas foi determinada por gravimetria em mufla a $550^{\circ} \mathrm{C}$ até obtenção de cinzas brancas (Nollet, 2004).

A proteína bruta foi quantificada mediante a determinação do nitrogênio total pelo método de Kjeldahl, conforme Association of Official Analytical Chemists (2000). O teor de lipídios foi determinado pela técnica de Soxhlet (1879), em que ocorre a extração com éter de petróleo a quente. O conteúdo de carboidratos disponíveis foi calculado por diferença, de acordo com Food and Agriculture Organization (2003). O conteúdo energético foi calculado utilizando fatores de conversão de $4,0 \mathrm{~kJ} \mathrm{~g}^{-1}$ para proteínas e carboidratos, e 9,0 kJ g-1 para lipídios (Food and Agriculture Organization, 2003).

As análises físico-químicas dos hambúrgueres foram realizadas em triplicata apenas no tempo zero, com exceção da umidade, que foi avaliada durante todo o período de armazenamento do produto.

\subsection{Avaliação da oxidação lipídica do hambúrguer de peixe}

A avaliação da oxidação lipídica do hambúrguer de peixe foi realizada nos tempos 0, 7, 14, 21 e 28 dias por duas metodologias distintas: método de índice de peróxidos, de acordo com American Oil Chemists Society (2003), e método de quantificação de substâncias reativas ao ácido tiobarbitúrico (TBARS) (Zhang et al., 2011).

\subsection{Análises microbiológicas do hambúrguer de peixe}

Foram realizadas as análises microbiológicas no hambúrguer de peixe nos tempos $0,7,14,21$ e 28 dias, previstas por legislação, para produtos à base de pescado refrigerados ou congelados (hambúrgueres e similares), de acordo com a RDC n. ${ }^{\circ}$ 12, de 2 de janeiro de 2001 (Brasil, 2001), que preconiza análise de coliformes a $45^{\circ} \mathrm{C}$, Estafilococos coagulase positiva e Salmonella sp. Paralelamente às análises exigidas por legislação, foi realizada a análise de contagem de mesófilos, com o intuito de complementar a análise microbiológica do alimento.

Os métodos microbiológicos foram realizados conforme Manual Analítico Bacteriológico (Bacteriological Analytical Manual) do FDA (Food and Drug Administration, 1998), com adaptações.

\subsection{Análises estatísticas}

As análises estatísticas foram realizadas utilizando os sistemas estatísticos Action Stat versão 3.1 (Estatcamp, 2017) e Design Expert ${ }^{\circledR} 7.0$ da Stat-Ease (Minneapolis, EUA). Os testes de estatística descritiva (média e desvio padrão) e de estatística inferencial (Teste de Tukey e ANOVA) foram aplicados nos resultados das análises cromatográficas, da quantificação de compostos fenólicos, flavonoides totais e atividade antioxidante, realizadas no extrato de erva-mate e nos resultados obtidos das análises físico-químicas e microbiológicas dos hambúrgueres.

\section{Resultados e discussão}

\subsection{Atividade antioxidante e quantificação de compostos fenólicos totais e flavonoides}

A Tabela 2 apresenta os resultados de atividade antioxidante do extrato de erva-mate e do BHA, avaliada pelos métodos de DPPH e FRAP, além dos resultados da quantificação de fenólicos totais e flavonoides.

Tabela 2. Resultados de DPPH, FRAP, fenólicos totais e flavonoides avaliados no extrato de erva-mate (Ilex paraguariensis - Heide Extratos Vegetais) e no BHA (butil-hidroxi-anisol - Henrifarma Produtos Químicos e Farmacêuticos).

\begin{tabular}{|c|c|c|c|c|}
\hline & $\begin{array}{c}\text { DPPH } \\
\left(\text { IC50 em } \mu \mathrm{g} \mathrm{mL}^{-1}\right)\end{array}$ & $\begin{array}{c}\text { FRAP } \\
\left(\mu \mathrm{mol} \text { de } \mathrm{Fe}(\mathrm{III}) \mathrm{g}^{-1}\right)^{1}\end{array}$ & $\begin{array}{c}\text { Fenólicos totais } \\
\qquad\left(\operatorname{EAG~g}^{-1}\right)^{2}\end{array}$ & $\begin{array}{c}\text { Flavonoides } \\
\left(\mathrm{EQ}^{-1}\right)^{3}\end{array}$ \\
\hline Erva-mate & $7,91 \pm 0,06$ & $4922,67 \pm 23,17$ & $104,54 \pm 0,00$ & $23,11 \pm 0,01$ \\
\hline BHA & $1,04 \pm 0,26$ & $15801,14 \pm 41,87$ & - & - \\
\hline
\end{tabular}

${ }^{1} \mu \mathrm{mol}$ de Fe (II) g-1: poder de redução em $\mu \mathrm{mol}$ de Fe (II) por grama de amostra; ${ }^{2}$ EAG g-1: equivalente a ácido gálico por grama de amostra; ${ }^{3}$ EQ g-1: equivalente a quercetina por grama de amostra. 
O método de $\mathrm{DPPH}$ expressou seu resultado por $\mathrm{IC}_{50} \mathrm{em} \mu \mathrm{g} \mathrm{mL} \mathrm{mL}^{-1}$, o qual se refere à concentração de ativo necessária para inibir 50\% do radical DPPH utilizado no teste (Neelambika \& Leelavathi, 2015). Verificase, na Tabela 2, que o BHA possui uma atividade antioxidante aproximadamente oito vezes superior à do extrato de erva-mate, uma vez que quanto menor a quantidade de ativo necessária para inibir $50 \%$ do radical $\mathrm{DPPH}$, maior seu poder antioxidante.

Dzabijeva et al. (2018) avaliaram a atividade antioxidante do extrato etanólico (50\%) de erva-mate e obtiveram valores de $\mathrm{IC}_{50}$ igual a $0,37 \mathrm{mg} \mathrm{mL}^{-1}$, o que demonstra uma baixa atividade antioxidante. Huang et al. (2014) demonstraram que a atividade antioxidante do extrato aquoso de erva-mate por DPPH foi de $\mathrm{IC}_{50}$ igual a $413 \mu \mathrm{g} \mathrm{mL}^{-1}$. De acordo com esses mesmos autores, os diferentes solventes utilizados para extração dos compostos, o tempo de contato, o processo de secagem e a época de colheita interferem na composição final do extrato e, consequentemente, na atividade biológica por este desempenhada, fato que pode justificar o resultado encontrado em nossa pesquisa.

No teste de quantificação do poder de redução de sulfato ferroso por FRAP, os resultados obtidos para o extrato de erva-mate e BHA foram de 4.922,67 e 15.801,14 $\mu$ mol de Fe (II) $\mathrm{g}^{-1}$ de amostra, respectivamente, o que comprova o alto poder antioxidante do BHA, visto que um grama do ativo é capaz de se complexar com $15.801,14 \mu \mathrm{mol}$ de $\mathrm{Fe}$ (III) a Fe (II). Vale ressaltar que o extrato em questão é composto por uma mistura de substâncias ativas e inativas (Miranda et al., 2015), que, por sua vez, podem interferir positivamente ou negativamente na atividade biológica avaliada.

A atividade antioxidante de extratos vegetais se deve à presença de compostos fenólicos, moléculas capazes de doar radicais de hidrogênio para parear com outros radicais livres disponíveis, retardando a oxidação e estabilizando o sistema (De Beer et al., 2002). Quanto à quantidade de compostos fenólicos totais, o extrato de erva-mate utilizado em nossa pesquisa apresentou exatamente 104,54 mg equivalente a ácido gálico por grama de amostra $\left(\mathrm{EAG} \mathrm{g}^{-1}\right)$, dos quais $23,11 \mathrm{mg}$ correspondem a flavonoides totais, expressos em equivalente a quercetina por grama de amostra $\left(\mathrm{EQG} \mathrm{g} \mathrm{g}^{-1}\right)$.

\subsection{Concentração Inibitória Mínima (CIM)}

Os resultados obtidos no ensaio de concentração inibitória mínima para a erva-mate foram de $10 \mathrm{mg} \mathrm{mL}^{-1}$ para Escherichia coli e Salmonella Typhi, e de $5 \mathrm{mg} \mathrm{mL}^{-1}$ para Staphylococcus aureus. O BHA apresenta valores de CIM de $0,313 \mathrm{mg} \mathrm{mL}^{-1}$ para os três microrganismos testados.

Prado Martin et al. (2013) estudaram a atividade antimicrobiana do extrato metanólico (M) e etanólico (E) da erva-mate contra patógenos em alimentos. Observaram resultados de CIM de 1,56 mg mL $\mathrm{mL}^{-1}(\mathrm{M})$ e 0,78 $\mathrm{mg} \mathrm{mL}^{-1}$ (E) para $S$. aureus, $3,13 \mathrm{mg} \mathrm{mL}^{-1}$ (M) e $6,25 \mathrm{mg} \mathrm{mL}^{-1}$ (E) para Salmonella enteritidis, e ausência de inibição para $E$. coli, nas concentrações testadas.

Sabe-se que o BHA é um conservante muito utilizado na indústria farmacêutica, com discreto poder antimicrobiano contra bactérias Gram positivas e negativas (Rowe et al., 2012). Seu potencial foi avaliado por Fernández-Álvarez et al. (2014), em combinações binárias com compostos fenólicos (preparados em etanol 10\%), em que foi observada concentração mínima inibitória de aproximadamente $1,49 \mathrm{mg} \mathrm{mL}^{-1}$ para S. aureus.

No teste de Concentração Bactericida Mínima (CBM), não foi observada eliminação completa dos microrganismos testados frente às concentrações avaliadas.

\subsection{Desenvolvimento e validação do método analítico}

O método por cromatografia líquida de ultra eficiência foi desenvolvido com base em levantamentos bibliográficos dos compostos de interesse contidos na erva-mate, a fim de elucidar suas estruturas e determinar os parâmetros de quantificação. Com base nesse levantamento, considerou-se, para a quantificação dos compostos da planta, um representante do grupo dos alcaloides (cafeína), um do grupo do 
ácido hidroxicinâmico (ácido clorogênico) e um do grupo dos flavonoides (rutina), principais responsáveis pelas atividades antioxidante e/ou antimicrobiana do extrato (Burris et al., 2012; Bojić et al., 2013).

O método proposto mostrou-se adequado para a análise dos compostos citados e, conforme observados na Tabela 3, os resultados estão de acordo com o preconizado pelo guia de validação de métodos em análises farmacêuticas (Ermer \& Miller, 2006), documento de orientação sobre validação de métodos analíticos do Imnetro (Coordenação Geral de Acreditação do Inmetro, 2011) e da RDC 166 de julho de 2017 (Brasil, 2017).

Tabela 3. Resultados obtidos nos parâmetros de linearidade, precisão, exatidão, limite de quantificação e detecção.

\begin{tabular}{|c|c|c|c|c|c|c|}
\hline Ativo & Linearidade $_{(\mathrm{R})}$ & $\begin{array}{c}\text { Repetibilidade } \\
\text { (DPR \%) }\end{array}$ & $\begin{array}{c}\text { Intermediária } \\
\text { (DPR \%) }\end{array}$ & $\begin{array}{c}\text { Exatidão } \\
\text { Recuperação } \\
(\%) \\
\end{array}$ & $\begin{array}{c}\mathrm{LQ} \\
\left(\mu \mathrm{g} \mathrm{mL}^{-1}\right)\end{array}$ & $\begin{array}{c}\text { LD } \\
\left(\mu \mathrm{g} \mathrm{mL}^{-1}\right)\end{array}$ \\
\hline $\begin{array}{l}\text { Ácido } \\
\text { clorogênico }\end{array}$ & 0,9991 & 3,81 & 1,74 & 99,19 & 0,15 & 0,04 \\
\hline Cafeína & 0,9996 & 1,40 & 1,93 & 99,63 & 0,17 & 0,05 \\
\hline Rutina & 0,9996 & 1,41 & 0,98 & 96,80 & 0,10 & 0,03 \\
\hline
\end{tabular}

LQ: Limite de quantificação; LD: Limite de detecção. Os valores representados consideram a média dos resultados de cada parâmetro.

\subsection{Quantificação de compostos por cromatografia líquida de ultraeficiência}

Os resultados obtidos para a quantificação dos compostos na amostra foram de 49,6 $\mathrm{mg} \mathrm{g}^{-1}$ para ácido clorogênico com Desvio Padrão Relativo (DPR) de 1,83\%, 34,5 $\mathrm{mg} \mathrm{g}^{-1}$ para cafeína com DPR de 0,36\% e $23,1 \mathrm{mg} \mathrm{g}^{-1}$ para rutina com DPR de $1,22 \%$.

Bojić et al. (2013) avaliaram o extrato aquoso de erva-mate por cromatografia líquida de alta eficiência e constataram a presença de $3 \mathrm{mg} \mathrm{g}^{-1}$ de ácido clorogênico, 2,3 $\mathrm{mg} \mathrm{g}^{-1}$ de rutina e 5,4 $\mathrm{mg} \mathrm{g}^{-1}$ de cafeína. Balzan et al. (2013) analisaram extratos aquosos, etanólico (70\%) e a fração em n-butanol de Ilex paraguariesis, e observaram a presença de $12,44,19,25$ e $6,52 \mathrm{mg} \mathrm{g}^{-1}$, respectivamente, de cafeína, e 16,12, 33,57 e $22,51 \mathrm{mg} \mathrm{g}^{-1}$, respectivamente, de ácido clorogênico.

A diferença pode ser associada ao processo extrativo aplicado às amostras, uma vez que diferentes solventes utilizados na extração, sob tempo de agitação e temperatura diferentes, podem promover a extração de diferentes compostos em diferentes quantidades (Dent et al., 2013).

\subsection{Atividade antioxidante combinada (extrato de erva-mate x BHA)}

Sabendo que o BHA é um antioxidante sintético com potencial citotóxico (Vandghanooni et al., 2013), é fundamental determinar qual a quantidade mínima pode ser associada a outro(s) composto(s) para se obter atividade antioxidante adequada. Os resultados de atividade antioxidante obtidos da avaliação da combinação entre extrato e BHA estão representadas na Figura 1, cujo ajuste matemático que se mostrou mais adequado foi um polinômio de grau dois com coeficiente de correlação de 0,9895 (Equação 1).

$\mathrm{R}=+0,00552778+0,048506 \times \mathrm{A}+0,15915 \times \mathrm{B}+(-0,00533 \times \mathrm{A} \times \mathrm{B})+0,0013266 \times \mathrm{A}^{2}-0,00700677 \times \mathrm{B}^{2}(1)$

Utilizando a Equação 1 (em que A se refere ao extrato de erva-mate e B ao BHA) e adotando a máxima quantidade de extrato testado $\left(10 \mu \mathrm{g} \mathrm{mL}^{-1}\right)$, é possível prever a quantidade de BHA mínima necessária para se obter a resposta máxima, que seria igual a $3,88 \mu \mathrm{g} \mathrm{mL}^{-1}$. 


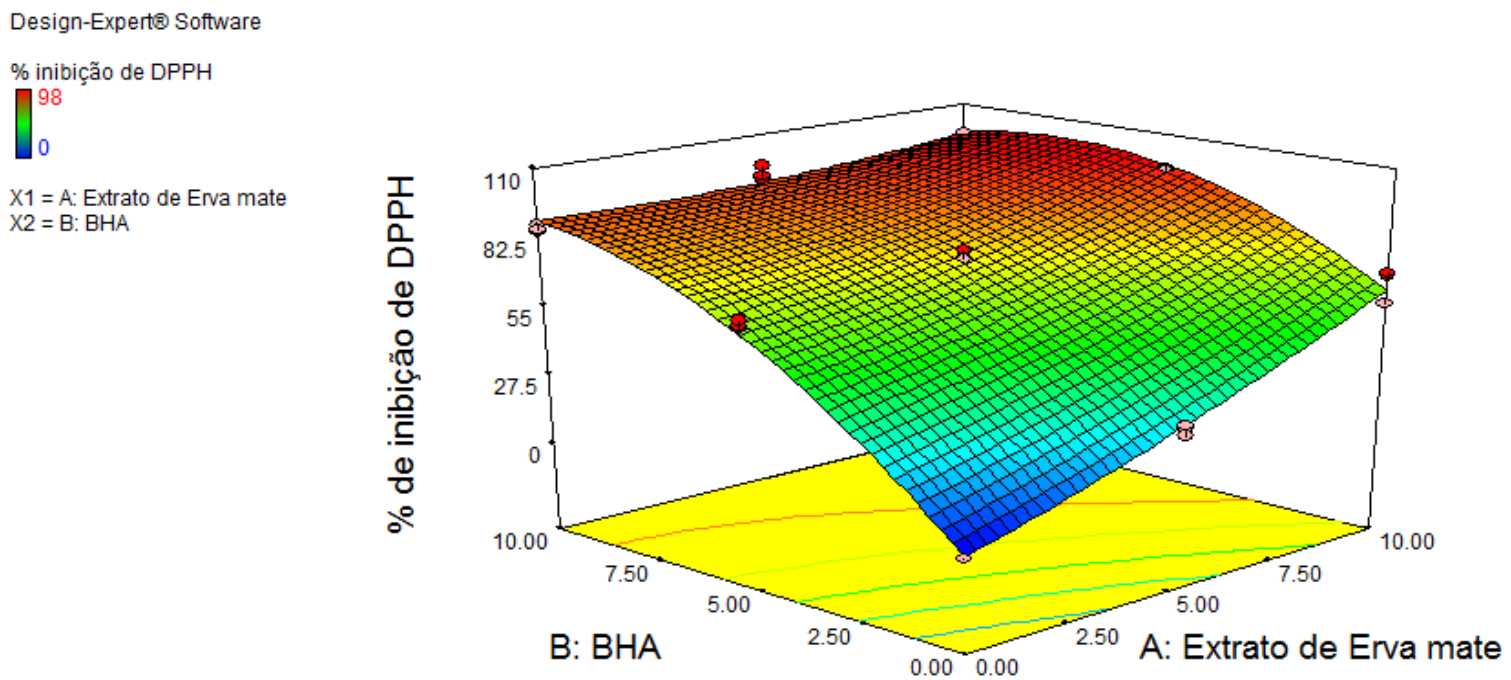

Figura 1. Superfície de resposta para porcentagem de inibição do radical DPPH em diferentes concentrações $\left(\mu g \mathrm{~mL}^{-1}\right)$ de BHA (B) e extrato de erva-mate (Ilex paraguariensis) (A) combinados.

A proposta de associar o conservante sintético com o extrato de erva-mate tem como finalidade reduzir a quantidade de conservante sintético sem perder a eficiência de conservação, além de promover efeitos benéficos tanto para a saúde do consumidor quanto à qualidade do produto.

\subsection{Interação antimicrobiana por checkerboard}

O teste de checkerboard foi executado associando o extrato de erva-mate e o butil-hidroxi-anisol, e o resultado obtido de ICIF para $S$. aureus foi de 0,998 , o que confere a essa associação um caráter aditivo. Segundo Nogueira (2012), valores de ICIF $\leq 0,5$ caracterizam interação sinérgica entre os compostos; entre 0,5 e 1,0, interação aditiva; entre 1,0 e 2,0, interação indiferente, e ICIF maior que 2,0 caracteriza interação antagônica entre os compostos, ou seja, cada composto exerce sua atividade sem interferência de um sobre o outro, seja esta sinérgica ou antagônica.

A proposta de avaliar a atividade sinérgica tanto entre extratos vegetais quanto entre extratos vegetais e conservantes sintéticos pretende elucidar fonte potencial de agentes antibacterianos naturais ou combinados, seguros e potentes, para aplicação na indústria. As interações sinérgicas de extratos vegetais podem potencializar a eficácia antibacteriana, reduzir a concentração dos ativos e efeitos secundários adversos promovidos por conservantes sintéticos, e favorecer a qualidade nutricional do alimento (Brusotti et al., 2014).

\subsection{Caracterização físico-química}

Os resultados das análises físico-químicas dos hambúrgueres de peixe estão expostos na Tabela 4.

Tabela 4. Composição química de hambúrgueres elaborados a partir de filés de tilápia do Nilo (Oreochromis niloticus), utilizando diferentes formulações nesta pesquisa

\begin{tabular}{ccccccc}
\hline Formulação & $\begin{array}{c}\text { Umidade } \\
\left.\mathbf{( g ~ 1 0 0 g}^{-1}\right)\end{array}$ & $\begin{array}{c}\text { Proteínas } \\
\left.\mathbf{( g ~ 1 0 0 g}^{-1}\right)\end{array}$ & $\begin{array}{c}\text { Cinzas } \\
\left(\mathbf{g ~ 1 0 0 g}^{-1}\right)\end{array}$ & $\begin{array}{c}\text { Lipídios } \\
\left.\mathbf{( g ~ 1 0 0 g}^{-1}\right)\end{array}$ & $\begin{array}{c}\text { Carboidrato } \\
\left(\mathbf{g ~ 1 0 0 g}^{-1}\right)\end{array}$ & $\begin{array}{c}\text { Energia } \\
\left(\mathbf{k c a l ~} \mathbf{~ 1 0 0 g}^{-1}\right)\end{array}$ \\
\hline F 1 & $71,08 \pm 0,65^{\mathrm{a}}$ & $16,74 \pm 1,30^{\mathrm{abc}}$ & $1,16 \pm 0,07^{\mathrm{b}}$ & $2,97 \pm 0,22^{\mathrm{a}}$ & 8,05 & 127,85 \\
F 2 & $71,62 \pm 0,78^{\mathrm{a}}$ & $18,10 \pm 0,87^{\mathrm{a}}$ & $1,25 \pm 0,02^{\mathrm{ab}}$ & $2,18 \pm 0,04^{\mathrm{a}}$ & 6,85 & 121,09 \\
F 3 & $71,59 \pm 0,58^{\mathrm{a}}$ & $17,20 \pm 0,86^{\mathrm{ab}}$ & $1,24 \pm 0,03^{\mathrm{ab}}$ & $2,54 \pm 0,41^{\mathrm{a}}$ & 7,43 & 123,19 \\
F 4 & $70,75 \pm 0,84^{\mathrm{a}}$ & $14,59 \pm 0,85^{\mathrm{bc}}$ & $1,28 \pm 0,05^{\mathrm{ab}}$ & $2,99 \pm 0,38^{\mathrm{a}}$ & 10,39 & 129,35 \\
F 5 & $71,11 \pm 0,59^{\mathrm{a}}$ & $14,74 \pm 0,73^{\mathrm{c}}$ & $1,32 \pm 0,07^{\mathrm{a}}$ & $2,63 \pm 0,40^{\mathrm{a}}$ & 10,20 & 125,91 \\
\hline
\end{tabular}

As formulações de hambúrguer de peixe, representadas a seguir, se referem a: F1 (controle); F2 (0,01\% de BHA); F3 (0,5\% de extrato de erva-mate); F4 ( $1,0 \%$ de extrato de erva-mate); F5 ( $0,03 \%$ de BHA). Valores seguidos de letras distintas na coluna diferem-se significativamente pelo Teste de Tukey $(\mathrm{p}<0,05)$; os resultados são expressos como média \pm desvio padrão (exceto carboidratos e energia). 
Pode-se observar que nenhuma das formulações apresentou diferença significativa para os testes de umidade e lipídios totais. Já para os demais testes da análise centesimal do hambúrguer de peixe, os resultados obtidos apresentaram diferenças significativas entre as formulações. Contudo, estas diferenças não afetam as características nutricionais do produto, uma vez que a legislação brasileira não define limites para hambúrgueres de peixe. No entanto, os valores para proteínas e lipídios estão próximos aos valores permitidos para hambúrguer produzidos a partir de outras fontes (Brasil, 2000).

Os valores para composição química para lipídios, proteínas e cinzas estão de acordo com o proposto por Costa (2017), que produziu hambúrguer a partir de filés de tilápias, apresentando variação em relação a umidade e carboidratos, em razão de diferenças na formulação. Mélo et al. (2014) também produziram hambúrguer a partir de tilápia, obtendo resultados de composição centesimal próximos aos desta pesquisa.

Os resultados de carboidratos apresentaram diferença significativa entre as formulações, avaliada pelo Teste de Tukey com significância de 5\%. No entanto, estes valores são calculados com base nos resultados de umidade, lipídios, proteínas e cinzas, que, por sua vez, já apresentam um desvio padrão individual, ou seja, há um desvio externo atribuído a esses resultados.

Pode-se verificar que as formulações 2, 3 e 4 não apresentaram diferença entre si em quantidade de cinzas; no entanto, observa-se diferença destas frente às formulações 1 e 5 . Considerando que a formulação 1 não possui nenhum insumo além de peixe, farinha de mandioca branca e sal, seu resultado de 1,16 grama de cinzas por 100 gramas de hambúrguer de peixe é justificado, uma vez que a porcentagem de peixe é maior neste tratamento e, este, por sua vez, possui alta umidade.

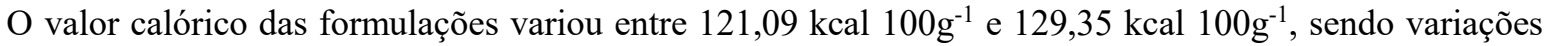
relacionadas à composição do produto. Em relação ao teor de umidade, que também foi avaliado durante os 28 dias de experimento, foi possível observar que não houve alterações ao longo do período.

\subsection{Avaliação da oxidação lipídica}

Não foi detectada oxidação lipídica em nenhuma das formulações testadas, tanto pelo método de índice de peróxido quanto pelo método de TBARS, e isto se deve, possivelmente, à baixa quantidade de lipídios presente nas formulações. Portanto, os resultados negativos de rancidez oxidativa encontrados em nossa pesquisa indicaram a boa qualidade dos hambúrgueres elaborados a partir de filés de tilápia, durante o período de 28 dias de estocagem refrigerada.

\subsection{Avaliação microbiológica}

As Figuras 2A e 2B apresentam os resultados obtidos das análises microbiológicas realizadas no hambúrguer de peixe por um período de 28 dias (quatro semanas).

Todas as formulações de hambúrgueres de filés de tilápia do Nilo obtiveram resultados de ausência para as análises de Staphylococcus coagulase positiva e Salmonella sp.

A especificação determinada pela RDC 12 de janeiro de 2001 para produtos à base de pescados ou congelados (hambúrgueres e similares) é de ausência de Salmonella sp. $25 \mathrm{~g}^{-1}$ de amostra; $1,0 \times 10^{3}$ Unidades Formadoras de Colônias por grama (UFC g ${ }^{-1}$ ) de amostra para Staphylococcus coagulase positiva, e de 1,0 $\times$ $10^{3} \mathrm{NMP} \mathrm{g}^{-1}$ de amostra para coliformes a $45^{\circ} \mathrm{C}$. Portanto, avaliando os resultados, pode-se considerar que o hambúrguer de peixe elaborado no presente trabalho atende às especificações de condições sanitárias e comprova segurança para o consumo do produto, confirmando as boas condições higiênico-sanitárias nas etapas do processamento, cuidado nas operações de limpeza e sanitização dos utensílios e equipamentos, além de precauções na manipulação do produto. 
A

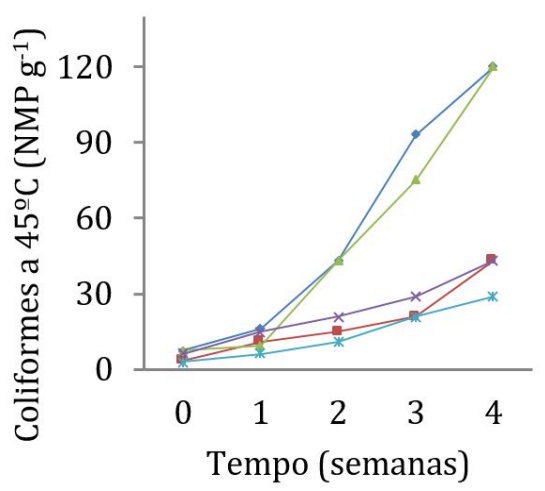

B

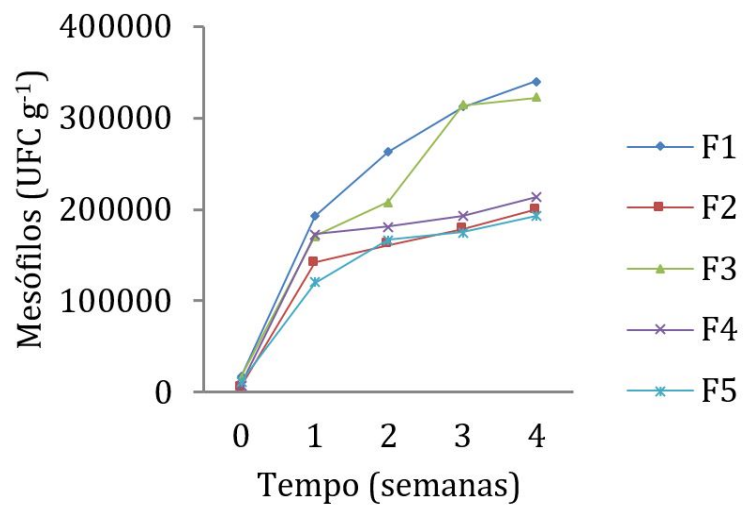

Figura 2. A: Resultados de coliformes termotolerantes das formulações de hambúrguer de peixe. B: Resultados de mesófilos das formulações de hambúrguer de peixe em que F1 (controle), F2 (0,01\% de BHA), F3 (0,5\% de extrato de erva-mate), F4 (1,0\% de extrato de erva-mate) e F5 (0,03\% de BHA) foram avaliadas por um período de quatro semanas.

Através de análise estatística por ANOVA, puderam-se avaliar os resultados de coliformes a $45^{\circ} \mathrm{C}$ dos diferentes tratamentos, obtidos ao longo dos 28 dias de experimento. As avaliações de variância foram aplicadas comparando o tratamento controle (sem adição de conservante) com as demais formulações, individualmente. Considerando a probabilidade de significância (valor de p), nenhuma das formulações apresentou diferença significativa quando foram comparadas com a formulação 1 (controle) para o referido teste, ou seja, a adição dos conservantes (natural ou sintético) não foi eficiente no controle de coliformes termotolerantes.

Os resultados obtidos da contagem de mesófilos também foram avaliados por ANOVA. Verificou-se que todos os tratamentos apresentaram diferenças significativas quando comparados com a formulação controle, exceto a formulação 3 , a qual compreende $0,5 \%$ do extrato de erva-mate. Nota-se que a formulação 1 apresenta valores crescentes mais expressivos das unidades formadoras de colônias, o que não ocorreu com as formulações 2, 4 e 5, já que o crescimento continuou mais lentamente. Neste caso, tanto o BHA quanto o extrato de erva-mate a $1 \%$ mostraram-se capazes de exercer um leve efeito conservante.

\section{Conclusão}

Neste estudo, pode-se verificar que o extrato de erva-mate apresentou compostos fenólicos e flavonoides que poderiam estar relacionados com as atividades biológicas antioxidante e antimicrobiana apresentadas. Foi possível observar que a associação de extrato com BHA diminuiu a quantidade de conservante sintético para se obter a mesma atividade antioxidante e mostrou caráter aditivo para $S$. aureus. O desenvolvimento de hambúrgueres de peixe incorporados com BHA ou $1 \%$ de extrato de erva-mate inibiu o crescimento de mesófilos durante os 28 dias de armazenamento, de forma que os compostos fenólicos quantificados (cafeína, rutina e ácido clorogênico) seriam os prováveis agentes conservantes.

A utilização de extrato de erva-mate no controle de crescimento microbiano em hambúrgueres de peixe mostrou-se uma proposta promissora para a utilização de produtos naturais na conservação de alimentos. Estudos adicionais devem ser realizados para a otimização das formulações, dos testes complementares e das análises sensoriais. 


\section{Agradecimentos}

À Universidade Tecnológica Federal do Paraná (UTFPR), pelo programa de mestrado e por toda a infraestrutura cedida para o desenvolvimento do projeto. À Empresa Prati Donaduzzi \& Cia Ltda. e à Fundação de Desenvolvimento Científico e Tecnológico (FUNDETEC), pelos equipamentos disponibilizados.

\section{Referências}

Association of Official Analytical Chemists - AOAC. (2000). Official Methods of Analysis of AOAC International. (17. ed., 1170 p.). Gaithersburg: AOAC.

American Oil Chemists Society - AOCS. (2003). Official method Cd 8 - 53. Peroxide Value. Official methods and recommended practices of the AOCS. Champaign: AOCS.

Atanasov, A. G., Waltenberger, B., Pferschy-Wenzig, E. M., Linder, T., Wawrosch, C., Uhrin, P., Temml, V., Wang, L., Schwaiger, S., Heiss, E. H., Rollinger, J. M., Schuster, D., Breuss, J. M., Bochkov, V., Mihovilovic, M. D., Kopp, B., Bauer, R., Dirsch, V. M., \& Stuppner, H. (2015). Discovery and resupply of pharmacologically active plant-derived natural products: A review. Biotechnology Advances, 33(8), 1582-1614. PMid:26281720. http://dx.doi.org/10.1016/j.biotechadv.2015.08.001

Balzan, S., Hernandes, A., Reichert, C. L., Donaduzzi, C., Pires, V. A., Gasparotto Junior, A., \& Cardozo Junior, E. L. (2013). Lipid-lowering effects of standardized extracts of llex paraguariensis in high-fat-diet rats. Fitoterapia, 86, 115-122. PMid:23422228. http://dx.doi.org/10.1016/j.fitote.2013.02.008

Bojić, M; Hass, V. S, Saric, D; Males, Z. (2013). Determination of flavonoids, phenolic acids, and xanthines in mate tea (Ilex paraguariensis St.-Hil.). Journal of Analytical Methods in Chemistry, 2013, 1-6.

Boroski, M., Visentainer, J. V., Cottica, S. M., \& Morais, D. R. (2015). Antioxidantes - Princípios e métodos analíticos (141p.). Curitiba: Ed. Appris.

Brasil Ministério da Agricultura, Pecuária e do Abastecimento. (2000, julho 31). Regulamento Técnico de Identidade e Qualidade de Hambúrguer (Instrução Normativa n 20, de 31 de julho de 2000). Diário Oficial [da] República Federativa do Brasil, Brasília.

Brasil Ministério da Saúde. Agência Nacional de Vigilância Sanitária - ANVISA. (2001, janeiro 10). Regulamento técnico sobre os padrões microbiológicos para alimentos (Resolução - RDC n 12, de 02 de janeiro de 2001). Diário Oficial [da] República Federativa do Brasil, Brasília.

Brasil Ministério da Saúde. Agência Nacional de Vigilância Sanitária - ANVISA. (2017, julho 25). Regulamento técnico sobre a validação de métodos analíticos e dá outras providências (Resolução - RDC n 166, de 24 de julho de 2017). Diário Oficial [da] República Federativa do Brasil, Brasília.

Brusotti, G., Cesari, I., Dentamaro, A., Caccialanza, G., \& Massolini, G. (2014). Isolation and characterization of bioactive compounds from plant resources: The role of analysis in the ethnopharmacological approach. Journal of Pharmaceutical and Biomedical Analysis, 87, 218-228. PMid:23591140. http://dx.doi.org/10.1016/j.jpba.2013.03.007

Burris, K. P., Harte, F. M., Davidson, P. M., Stewart, C. N., \& Zivanovic, S. (2012). Composition and bioactive properties of yerba mate (Ilex paraguariensis A. St.-Hil.): a review. Chilean Journal of Agricultural Research, 72(2), 268-274. http://dx.doi.org/10.4067/S0718-58392012000200016

Cardozo Junior, E. L., \& Morand, C. (2016). Interest of mate (Ilex paraguariensis A. St.-Hil.) as a new natural functional food to preserve human cardiovascular health - A review. Journal of Functional Foods, 21, 440-454. http://dx.doi.org/10.1016/j.jff.2015.12.010

Clinical and Laboratory Standards Institute - CLSI. (2015). Methods for dilution antimicrobial susceptibility tests for bacteria that grow aerobically (10th ed.). Wayne: CLSI.

Costa, D. P. S. (2017). Desenvolvimento de hambúrguer com carne mecanicamente separada de carcaça e de refile de tilápia: caracterização microbiológica, físico-química e sensorial (Tese de doutorado em Engenharia e Ciência de Alimentos). Universidade Estadual Paulista "Júlio de Mesquita Filho", São José do Rio Preto.

Coordenação Geral de Acreditação do Inmetro - CGCRE. (2011). Orientação Sobre Validação de Métodos Analíticos. DOQCGCRE-008/04. Rio de Janeiro: CGCRE.

De Beer, D., Joubert, E., Gelderblom, W. C. A., \& Manley, M. (2002). Phenolic compounds: A review of their possible role as in vivo antioxidants of wine. South African Journal of Enology and Viticulture, 23(2), 48-61.

Dent, M., Dragovic-Uzelac, V., Penic, M., Brncic, M., \& Bosiljkov, T. (2013). The effect of extraction solvents, temperature and time on the composition and mass fraction of polyphenols in Dalmatian wild sage (Salvia officinalis L.) extracts. Food Technology and Biotechnology, 51(1), 84-91.

Dzabijeva, D., Boroduske, A., Ramata-Stunda, A., Mazarova, N., Nikolajeva, V., Boroduskis, M., \& Nakurte, I. (2018). AntiBacterial Activity and Online HPLC-DPPH Based Antiradical Kinetics of Medicinal Plant Extracts of High Relevance for Cosmetics Production. Key Engineering Materials, 762, 8-13. http://dx.doi.org/10.4028/www.scientific.net/KEM.762.8.

Endo, E. H., Cortez, D. A. G., Ueda-Nakamura, T., Nakamura, C. V., \& Dias Filho, B. P. (2010). Potent antifungal activity of extracts and pure compound isolated from pomegranate peels and synergism with fluconazole against Candida albicans. Research in Microbiology, 161(7), 534-540. PMid:20541606. http://dx.doi.org/10.1016/j.resmic.2010.05.002 
Ermer, J., \& Miller, J. H. Method validation in pharmaceutical analysis: A guide to best practice. Weinheim: John Wiley \& Sons, 2006

ESTATCAMP. (2017). Software Action. Consultoria em estatística e qualidade. São Carlos: Estatcamp.Fernández-Álvarez, L., Del Valle, P., Arriaga, D., García-Armesto, M. R., \& Rúa, J. (2014). Binary combinations of BHA and other natural and synthetic phenolics: Antimicrobial activity against Staphylococcus aureus and antioxidant capacity. Food Control, 42, 303-309. http://dx.doi.org/10.1016/j.foodcont.2014.02.020

Food and Agriculture Organization - FAO. (2003). Food Energy - Methods of analysis and conversion factors (Food and Nutrition Paper 77). Rome: FAO.

Food and Drug Administration - FDA. (1998). Bacteriological Analytical Manual. Revision A. Silver Spring: FDA.

Guerreiro, L. (2006). Dossiê técnico - produção de hambúrguer. Rio de Janeiro: REDETEC.

Heck, C. I., \& De Mejia, E. G. (2007). Yerba Mate Tea (llex paraguariensis): a comprehensive review on chemistry, health implications, and technological considerations. Journal of Food Science, 72(9), R138-R151. PMid:18034743. http://dx.doi.org/10.1111/j.1750-3841.2007.00535.x

Huang, W. Y; Lee, P. C; Hsu, J. C; Lin, Y. R; Chen, H. J; Lin, Y. S. (2014). Effects of water quality on dissolution of yerba mate extract powders. The Scientific World Journal, 2014, 1-6. http://dx.doi.org/10.1155/2014/768742.

International Council for Harmonisation - ICH. (2005). Harmonized Tripartite. Validation of Analytical Procedures: Text and Methodology. Q2 (R1) (Vol. 1). Geneva: ICH.

Mélo, H. M. G., Galvão, S. M. R., Silva, J. G., Maciel, M. I. S., Moreira, R. T., Andrade, S. A. C., \& Mendes, E. S. (2014). Qualidade do fishbúrger de carne mecanicamente separada de tilápia do nilo adicionado de fibra de trigo e óleo de milho. Ars Veterinária, 30(1), 23-31. http://dx.doi.org/10.15361/2175-0106.2014v30n1p23-31

Miranda, J. A. L., Rocha, J. A., Araujo, K. M., Quelemes, P. V., Mayo, S. J., \& Andrade, I. M. (2015). Atividade antibacteriana de extratos de folhas de Montrichardia linifera (Arruda) Schott (Araceae). Revista Brasileira de Plantas Medicinais, 17(4, Supl.3), 1142-1149. http://dx.doi.org/10.1590/1983-084x/14_169

Neelambika, H. S. \& Leelavathi, S. (2015). Comparative antioxidant activity of whole plant of Blepharis maderaspatensis (L.) Heyne ex Roth. and Blepharis molluginifolia Pers. of Mysore district by DPPH method. Indo American Journal of Pharmacy Research, 5(3), 1191-1196.

Nogueira, L. G. (2012). Avaliação do potencial antimicrobiano de Pouteria spp. e de triterpenos quinonametídeos com enfoque no Helicobacter pylori. (Tese de doutorado em Ciências Farmacêuticas). Universidade Estadual Paulista "Júlio de Mesquita Filho", Araraquara.

Nollet, L. M. L. (2004). Handbook of food analysis. Physical Characterization and Nutrient Analysis (2. ed., vol. 1). New York: Marcel Dekker, Inc.

Pagliosa, C. M., Vieira, M. A., Podesta, R., Maraschin, M., Zeni, A. L. B., Amante, E. R., \& Amboni, R. D. M. C. (2010). Methylxanthines, phenolic composition, and antioxidant activity of bark from residues from mate tree harvesting (llex paraguariensis A. St. Hil.). Food Chemistry, 122(1), 173-178. http://dx.doi.org/10.1016/j.foodchem.2010.02.040Prado Martin, J. G., Porto, E., Alencar, S. M., Glória, E. M., Corrêa, C. B., \& Ribeiro Cabral, I. S. (2013). Antimicrobial activity of yerba mate (Ilex paraguariensis St. Hil.) against food pathogens. Revista Argentina de Microbiologia, 45(2), 93-98. PMid:23876271. http://dx.doi.org/10.1016/S0325-7541(13)70006-3

Rufino, M. S. M., Alves, R. E., Brito, E. S., Morais, S. M., Sampaio, C. G., Pérez-Jiménez, J. \& Saura-Calixto, F. D. (2007). Metodologia Científica: Determinação da atividade antioxidante total em frutas pela captura do radical livre DPPH (Comunicado Técnico, 127). Fortaleza: Embrapa. Recuperado em 2016, Outubro 24, de http:/l https://ainfo.cnptia.embrapa.br/digital/bitstream/CNPAT/10224/1/Cot_127.pdf.

Rowe, R. C., Sheskey, P. J., Cook, W. G., \& Fenton, M. E. (2012). Handbook of Pharmaceutical Excipients (vol. 7). Washington: Pharmaceutical Press.

Soxhlet, F. (1879). The weight analytic determination of milk fat. Polytechnisches Journal, 232, 461-465.

Tiwari, B. K., Valdramidis, V. P., O'Donnell, C. P., Muthukumarappan, K., Bourke, P., \& Cullen, P. J. (2009). Application of natural antimicrobials for food preservation. Journal of Agricultural and Food Chemistry, 57(14), 5987-6000. PMid:19548681. http://dx.doi.org/10.1021/jf900668n

Vandghanooni, S., Forouharmehr, A., Eskandani, M., Barzegari, A., Kafil, V., Kashanian, S., \& Ezzati Nazhad Dolatabadi, J. (2013). Cytotoxicity and DNA fragmentation properties of butylated hydroxyanisole. DNA and Cell Biology, 32(3), 98-103. PMid:23413972. http://dx.doi.org/10.1089/dna.2012.1946

Zhang, L., Li, X., Lu, W., Shen, H., \& Luo, Y. (2011). Quality predictive models of grass carp (Ctenopharyngodon idellus) at different temperatures during storage. Food Control, 22(8), 1197-1202. http://dx.doi.org/10.1016/j.foodcont.2011.01.017 